\title{
COMMENTARY
}

\section{The next generation of peptide receptor radionuclide therapy}

\author{
Tessa Brabander $1, *$, Julie Nonnekens ${ }^{1,2, *}$ and Johannes Hofland ${ }^{3}$ \\ ${ }^{1}$ ENETS Center of Excellence, Department of Radiology \& Nuclear Medicine, Erasmus Medical Center, Rotterdam, The Netherlands \\ 2Department of Molecular Genetics, Erasmus Medical Center, Rotterdam, The Netherlands \\ ${ }^{3}$ ENETS Center of Excellence, Section of Endocrinology, Department of Internal Medicine, Erasmus Cancer Institute, Erasmus Medical Center, Rotterdam, \\ The Netherlands
}

Correspondence should be addressed to J Hofland: j.hofland@erasmusmc.nl

*(T Brabander and J Nonnekens contributed equally to this work)

\begin{abstract}
Peptide receptor radionuclide therapy (PRRT) with [177Lu]Lu-DOTA-[Tyr3]octreotate has been successfully developed in the last decades for the treatment of neuroendocrine neoplasms. However, different methods to improve the objective response rate and survival are under investigation. This includes changes of the radioligand, dosimetry and combination therapy with different agents, such as radiosensitisers. Hofving et al. recently reported, in the April 2019 issue of Endocrine-Related Cancer, the use of heat-shock protein 90 (Hsp90) modulation to augment radiation effects as a new promising target for radiosensitisation. In this commentary, new developments in the field of PRRT are discussed, placing these new findings about Hsp90 inhibitors into context.
\end{abstract}

\section{Background}

Well-differentiated neuroendocrine neoplasms (NENs) of the gastroenteropancreatic system are characterised by a low mutational burden and indolent tumour growth. These features contribute to the poor success rates of cytotoxic chemotherapy in NENs in terms of reduction of tumour size or duration of progression-free survival (PFS). This has triggered the development of therapeutic approaches aimed at established targets in welldifferentiated gastroenteropancreatic (GEP) NENs, such as the somatostatin receptor (SST), mammalian target of rapamycin (mTOR) pathway or vascular endothelial growth factor (VEGF) (Raymond et al. 2011, Yao et al. 2011, Caplin et al. 2014). Following the advent of somatostatin analogues (SSAs) for the treatment of NENrelated hormonal symptoms and for NEN diagnostics (Krenning et al. 1989), radiolabelled SSAs were developed for therapy as a Trojan horse strategy to locally irradiate the tumour, an approach coined peptide receptor radionuclide therapy (PRRT) (Kwekkeboom et al. 2005). This was successfully implemented for [90Y]Y-DOTA-[Tyr3] octreotide ( ${ }^{90}$ Y-DOTATOC) and [177Lu]Lu-DOTA-[Tyr3] octreotate (177Lu-DOTATATE), with the latter radioligand now registered for therapy of well-differentiated GEP NENs, also termed GEP neuroendocrine tumours (NETs).

PRRT with ${ }^{177} \mathrm{Lu}$-DOTATATE is a potent therapy with approximately $40 \%$ of patients obtaining a partial response and $80 \%$ of patients obtaining disease control after four cycles (Brabander et al. 2017). In the phase 3 NETTER-1 trial, PFS after four cycles of PRRT was estimated at 30 months and there was a 79\% decrease in the risk of instantaneous progression or death in midgut NET patients treated with ${ }^{177} \mathrm{Lu}$-DOTATATE PRRT compared to 


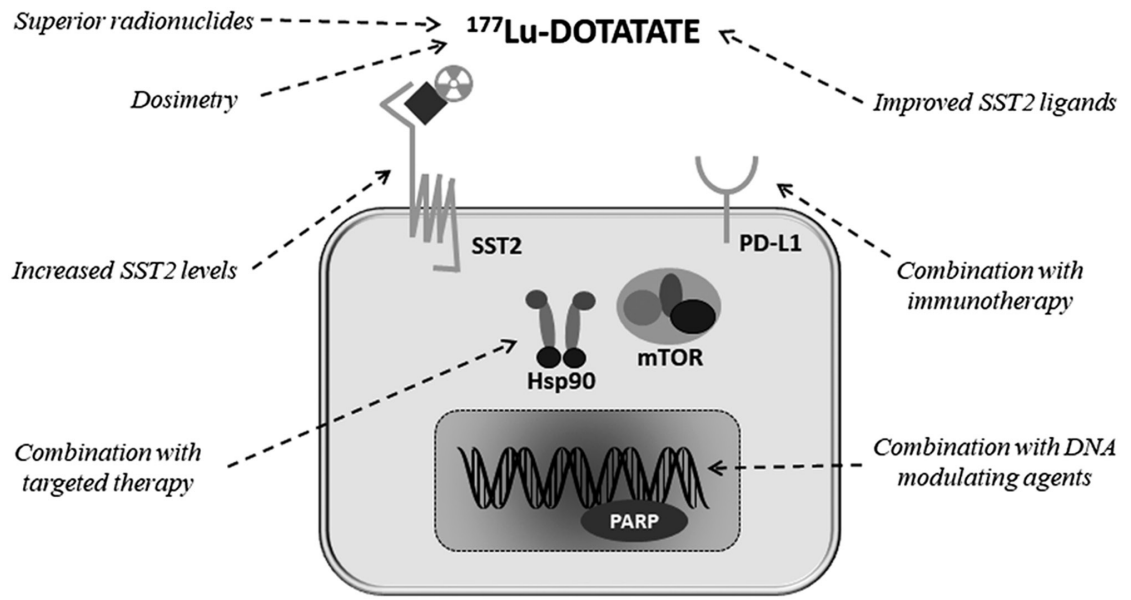

Figure 1

Future prospects to improve peptide receptor radionuclide therapy in patients. Hsp90, heat shock protein 90; mTOR, mammalian target of rapamycin; PARP, poly ADP-ribose polymerase; PD-L1, programmed death ligand-1; SST2, somatostatin receptor type 2 . those randomised to a high-dose unlabelled SSA (Strosberg et al. 2017). Despite this efficacy, not all patients respond favourably and adverse effects, predominantly on the kidneys and bone marrow, are observed in a minority of patients. Consequently, optimising PRRT is of key importance to improve efficacy while reducing toxicity in NEN patients. Hofving et al. recently reported, in the April 2019 issue of Endocrine-Related Cancer (volume 26, pages 437-449, https://doi.org/10.1530/EC-18-0509), the use of heat-shock protein 90 (Hsp90) modulation to augment radiation effects (Hofving et al. 2019). Here, we put these findings into the context of emerging therapeutic strategies for superior PRRT outcome (Fig. 1).

\section{Radionuclides}

The use of radionuclides emitting higher energy levels in PRRT can potentially increase the level of cancer cell death induction. New radionuclides that are introduced for PRRT besides Lutetium-177 $\left({ }^{177} \mathrm{Lu}\right)$ and Yttrium-90 $\left.{ }^{(90} \mathrm{Y}\right)$ are mainly alpha emitting radionuclides, such as Bismuth-213 $\left.{ }^{213} \mathrm{Bi}\right)$, Actinium-225 $\left({ }^{225} \mathrm{Ac}\right)$ and Lead$212\left({ }^{212} \mathrm{~Pb}\right)$. The high-energy radiation emitted by these alpha radionuclides will increase the number of DNA double-strand breaks and therefore cell death. One of the disadvantages of alpha therapy is the potential release of daughter radionuclides from the chelator. This can result in the circulation of radionuclides with a long half-life, possibly causing unintended and severe toxicity. The literature regarding targeted alpha therapy with ${ }^{213} \mathrm{Bi}$ or ${ }^{225} \mathrm{Ac}$ is scarce with limited number of patients. However, the first results are promising (Kratochwil et al. 2014). There is still a need for good clinical trials regarding the dose limited toxicity and efficacy. Recently, a phase 1 study was started with ${ }^{212 P b-D O T A M T A T E ~(N C T 03466216) . ~}$

\section{Dosimetry}

PRRT is regularly administered using a fixed injected activity of $7.4 \mathrm{GBq}$ per cycle, which results in variable absorbed doses to the tumour and healthy organs, due to the large patient's variability in biodistribution of the radiolabelled peptides. Individual dosimetry-based adaptation of administered activity can therefore be used to create optimised treatment protocols. Dosimetry can be based on pre-PRRT positron emission tomography (PET) with Gallium-68-labelled SSAs or post-PRRT single-photon emission computed tomography (SPECT) scanning. For example, the group from Uppsala performed dosimetry based on planar whole-body and SPECT/CT images of the abdomen and also in a sub-selection of patients in blood and urine samples. In 50\% of patients more than four cycles of $7.4 \mathrm{GBq}$ could be administered and patients were treated with up to ten cycles (Sandstrom et al. 2013). A Canadian group performed dosimetry based on the renal-absorbed dose. Following a first dose based on the glomerular filtration rate and the body surface area, subsequent cycle doses were based on post-therapy scan dosimetry. The results were encouraging without extra toxicity (Del Prete et al. 2019), showing that personalised dose calculation can improve the absorbed tumour dose. However, larger clinical studies should proof feasibility and efficacy of the individual dosimetry-based strategy for PRRT improvement.

\section{Antagonists}

For many years, it was believed that receptor internalisation is essential for high tumour uptake and long residence time of the radioligand. However, Ginj et al. found a significantly higher tumour uptake in mice injected with the somatostatin antagonist [111In]In-DOTA-sst3-ODN-8 
and [111In]In-DOTA-sst2-ANT compared to agonists (Ginj et al. 2006). Also, in a direct comparison in mice not only a higher uptake, but also a longer survival and better tumour control was observed in mice treated with the antagonist ${ }^{177}$ Lu-DOTA-JR11 (Dalm et al. 2016). In patients, the first pilot study demonstrated promising results with a 1.7-10.6 times higher tumour dose with the antagonist ${ }^{177} \mathrm{Lu}-\mathrm{DOTA}-J R 11$ compared to ${ }^{177} \mathrm{Lu}$-DOTATATE (Cescato et al. 2011). Antagonists are currently under investigation for both imaging and therapy in different phase I/II trials. The main concern of these new peptides is the increase of uptake in kidneys and bone marrow, resulting in higher toxicity. The introduction of an amino acids infusion lowers the radiation dose on the kidneys significantly, making the kidneys no longer the dose-limiting organ

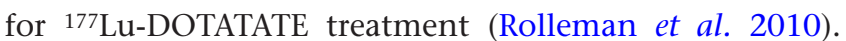
However, with the introduction of new peptides and radionuclides, it is essential to perform dosimetry and calculate the dose on the different organs to prevent side effects.

\section{Somatostatin receptor type 2}

Radioiodine therapy for thyroid diseases is potentiated by stimulating iodine uptake with thyroid-stimulating hormone (TSH), either through thyroid hormone withdrawal or the administration of recombinant TSH (Ladenson et al. 1997). Similar strategies to improve radiolabelled SSA binding includes epigenetic modulation of the SST type 2 (SST2) gene. Three preclinical studies have shown that inhibition of histone deacetylase activity can augment SST2 expression up to two-fold and SSA binding in NET cells up to six-fold (Arvidsson et al. 2016, Taelman et al. 2016, Veenstra et al. 2018). A comparable stimulating effect on SST2 levels was provoked by the methyltransferase inhibitor azacitidine (Veenstra et al. 2018). Epigenetic modifications near the SST2 gene can thus induce target expression and potentially improve radioligand targeting.

\section{Radiosensitisation}

PRRT induces various types of damage in the tumour cell DNA. While a certain amount of DNA damage can be repaired, a higher level will induce cell death. Thus, DNA damage repair counteracts therapy efficacy. To overcome the current limitations of PRRT, DNA damage repair inhibitors can be used as radiosensitisers of PRRT to expand the therapeutic window. This approach can increase the level of DNA damage in the tumour and a similar dose of PRRT will therefore lead to a higher cell death rate. It has previously been shown preclinically that PRRT can be augmented by Poly ADP-ribose polymerase (PARP) inhibitors (Nonnekens et al. 2016, Purohit et al. 2018). A similar approach successfully tested in vivo is the combination of PRRT with a nicotineamide phosphoribosyltransferase (NAMPT) inhibitor that blocks nicotinamide-adenine-dinucleotide $\left(\mathrm{NAD}^{+}\right)$regeneration after consumption by PARP. The NAMPT inhibitor GMX1778 produced a synergistic antitumor effect on GOT1 xenografts in mice treated with PRRT (Elf et al. 2017). Furthermore, a preclinical study showed that Hedgehog inhibitors can function as radiosensitisers of PRRT. The Hedgehog pathway is commonly upregulated in cancer, and radiosensitisation is achieved by inhibition of the PI3K/AKT/mTOR activation of the Hedgehog signalling pathway, which is activated by PRRT (Spetz et al. 2017). Another way of radiosensitisation is by using 5-fluoro-uracil (5-FU) (Kashyap et al. 2015). 5-FU is a chemotherapeutic agent that prevents de novo DNA synthesis via inhibition of thymidylate synthase. Results of a randomised controlled trial from our institute comparing PRRT and PRRT with the radiosensitiser capecitabine are expected in 2019.

\section{Hsp90 inhibition}

Potentiation of PRRT can be obtained through modulation of the cellular response to the radiation-induced DNA damage. This was the rationale behind the study of Hofving et al., where a drug library of 1224 compounds was tested in GOT1 and P-STS cells for synergy with external radiation (Hofving et al. 2019). This screen detected several potential synergistic drugs within relevant NET pathways, including the above mentioned mTOR/PI3K, tyrosine kinase receptors and histone deacetylases. A novel radiosensitiser that was detected in both cell lines was the bromodomain and extra-terminal motif (BET) proteins, involved in histone acetylation recognition and support of transcriptional complexes. Inhibitors of BET proteins are currently in clinical trial phase for several types of carcinomas (Fu et al. 2015). The drug screen in the grade 3 tumour-derived P-STS cells revealed a predominance of G protein-coupled receptor targets, which offers novel insights into PRRT-mediated cellular responses. 
Hsp90 was the most potent target in the welldifferentiated GOT-1 cell line and was subject to further confirmatory studies. As a molecular chaperone involved in the response to DNA, inhibition of Hsp90 has been shown as a viable target for radiosensitisation (Russell et al. 2003). Importantly, this effect was not observed in the P-STS cell line, possibly reflecting a lack of efficacy of Hsp90 inhibitors in high-grade tumours. Hsp90 expression was found to be increased in small intestinal NET cells relative to tumour stroma and the synergy of Hsp90 inhibition with radiation was confirmed in patient NET tissues ex vivo. Overall, their innovative drug screen approach offers several novel targets that warrant further investigation for combining targeted treatment with PRRT.

\section{Immunotherapy}

Besides inducing DNA damage leading to (tumour) cell death, radiation therapy can reprogram the tumour microenvironment to induce an antitumor immune response. However, it can also induce an immunosuppressive response. The interaction of programmed death ligand 1 (PD-L1) on tumour cells with programmed cell death protein 1 (PD-1) on T-cells reduces T-cell functionality, thus reducing the control of the immune system on the tumour cells. PD-1 and PD-L1 inhibitors block this interaction and increase the T-cell response to kill tumours (Weber 2010). Besides using these immunosuppressive drugs as monotherapy, they can also increase the cell killing potential of external radiation therapy (Weichselbaum et al. 2017). It can therefore be expected that PRRT in combination with immunotherapy might be beneficial for some patients. However, it needs to be taken into consideration that characteristics of the immune infiltrate can influence immunotherapy efficacy. Approximately $1 / 3$ of G1/G2 GEP- and lung-NETs are PD-L1 positive (Mehnert et al. 2017). Furthermore, PD-L1 expression appears to increase in poorly differentiated neuroendocrine carcinomas, thus suggesting that combination therapy of PRRT with PD-1 or PD-L1 inhibitors might be more favourable in patients with poor prognosis (Cavalcanti et al. 2017).

\section{Conclusion}

With the approval of ${ }^{177} \mathrm{Lu}$-DOTATATE for GEP NETs, this therapy has become available for many patients worldwide. Results are favourable, but there is still room for improvement. In the last decades, many new developments have been made. The drug screen method presented by Hofving et al. has uncovered several promising targets for radiosensitisation including Hsp90 inhibition. Their findings coincide with other developments in radioligands, receptor expression and radiosensitisation. These methods may offer a synergistic effect with PRRT and consequently increase response rates and survival. The future of PRRT is promising, but the majority of currently published research is still in preclinical stages and proof-of-concept studies in NET patient are highly needed. Of particular note, the safety concerning radiation to healthy tissues requires detailed consideration and assessment when combining novel cytotoxic modalities.

\section{Declaration of interest}

J N has an investigator-initiated project contract with Advanced Accelerator Applications, a Novartis company. J H has served on the advisory board for Novartis. T B has nothing to disclose.

\section{Funding}

This work did not receive any specific grant from any funding agency in the public, commercial or not-for-profit sector.

\section{References}

Arvidsson Y, Johanson V, Pfragner R, Wangberg B \& Nilsson O 2016 Cytotoxic effects of valproic acid on neuroendocrine tumour cells. Neuroendocrinology 103 578-591. (https://doi. org/10.1159/000441849)

Brabander T, van der Zwan WA, Teunissen JJM, Kam BLR, Feelders RA, de Herder WW, van Eijck CHJ, Franssen GJH, Krenning EP \& Kwekkeboom DJ 2017 Long-term efficacy, survival, and safety of [177Lu-DOTA0,Tyr3]octreotate in patients with gastroenteropancreatic and bronchial neuroendocrine tumors. Clinical Cancer Research 23 4617-4624. (https://doi. org/10.1158/1078-0432.CCR-16-2743)

Caplin ME, Pavel M, Cwikla JB, Phan AT, Raderer M, Sedlackova E, Cadiot G, Wolin EM, Capdevila J, Wall L, et al. 2014 Lanreotide in metastatic enteropancreatic neuroendocrine tumors. New England Journal of Medicine 371 224-233. (https://doi.org/10.1056/ NEJMoa1316158)

Cavalcanti E, Armentano R, Valentini AM, Chieppa M \& Caruso ML 2017 Role of PD-L1 expression as a biomarker for GEP neuroendocrine neoplasm grading. Cell Death and Disease 8 e3004. (https://doi.org/10.1038/cddis.2017.401)

Cescato R, Waser B, Fani M \& Reubi JC 2011 Evaluation of 177Lu-DOTA-sst2 antagonist versus 177Lu-DOTA-sst2 agonist binding in human cancers in vitro. Journal of Nuclear Medicine $\mathbf{5 2}$ 1886-1890. (https://doi.org/10.2967/jnumed.111.095778)

Dalm SU, Nonnekens J, Doeswijk GN, de Blois E, van Gent DC, Konijnenberg MW \& de Jong M 2016 Comparison of the therapeutic response to treatment with a $177 \mathrm{Lu}-$ labeled somatostatin receptor agonist and antagonist in preclinical models. Journal of Nuclear Medicine 57 260-265. (https://doi.org/10.2967/jnumed.115.167007) (c) 2019 Society for Endocrinology Published by Bioscientifica Ltd. Printed in Great Britain 
Del Prete M, Buteau FA, Arsenault F, Saighi N, Bouchard LO, Beaulieu A \& Beauregard JM 2019 Personalized (177)Lu-octreotate peptide receptor radionuclide therapy of neuroendocrine tumours: initial results from the P-PRRT trial. European Journal of Nuclear Medicine and Molecular Imaging 46 728-742. (https://doi.org/10.1007/s00259-0184209-7)

Elf AK, Bernhardt P, Hofving T, Arvidsson Y, Forssell-Aronsson E, Wangberg B, Nilsson O \& Johanson V 2017 NAMPT inhibitor GMX1778 enhances the efficacy of 177Lu-DOTATATE treatment of neuroendocrine tumors. Journal of Nuclear Medicine 58 288-292. (https://doi.org/10.2967/jnumed.116.177584)

Fu LL, Tian M, Li X, Li JJ, Huang J, Ouyang L, Zhang Y \& Liu B 2015 Inhibition of BET bromodomains as a therapeutic strategy for cancer drug discovery. Oncotarget 6 5501-5516. (https://doi.org/10.18632/ oncotarget.3551)

Ginj M, Zhang H, Waser B, Cescato R, Wild D, Wang X, Erchegyi J, Rivier J, Macke HR \& Reubi JC 2006 Radiolabeled somatostatin receptor antagonists are preferable to agonists for in vivo peptide receptor targeting of tumors. PNAS 103 16436-16441. (https://doi. org/10.1073/pnas.0607761103)

Hofving T, Sandblom V, Arvidsson Y, Shubbar E, Altiparmak G, Swanpalmer J, Almobarak B, Elf AK, Johanson V, Elias E, et al. 2019 177Lu-octreotate therapy for neuroendocrine tumours is enhanced by Hsp90 inhibition. Endocrine-Related Cancer 26 437-449. (https:// doi.org/10.1530/ERC-18-0509)

Kashyap R, Hofman MS, Michael M, Kong G, Akhurst T, Eu P, Zannino D \& Hicks RJ 2015 Favourable outcomes of (177) Lu-octreotate peptide receptor chemoradionuclide therapy in patients with FDG-avid neuroendocrine tumours. European Journal of Nuclear Medicine and Molecular Imaging 42 176-185. (https://doi. org/10.1007/s00259-014-2906-4)

Kratochwil C, Giesel FL, Bruchertseifer F, Mier W, Apostolidis C, Boll, Murphy K, Haberkorn U \& Morgenstern A 2014 Bi-DOTATOC receptor-targeted alpha-radionuclide therapy induces remission in neuroendocrine tumours refractory to beta radiation: a first-inhuman experience. European Journal of Nuclear Medicine and Molecular Imaging 41 2106-2119. (https://doi.org/10.1007/s00259-014-2857-9)

Krenning EP, Bakker WH, Breeman WA, Koper JW, Kooij PP, Ausema L, Lameris JS, Reubi JC \& Lamberts SW 1989 Localisation of endocrinerelated tumours with radioiodinated analogue of somatostatin. Lancet 1 242-244. (https://doi.org/10.1016/s0140-6736(89)91258-0)

Kwekkeboom DJ, Teunissen JJ, Bakker WH, Kooij PP, de Herder WW, Feelders RA, van Eijck CH, Esser JP, Kam BL \& Krenning EP 2005 Radiolabeled somatostatin analog [177Lu-DOTA0,Tyr3]octreotate in patients with endocrine gastroenteropancreatic tumors. Journal of Clinical Oncology 23 2754-2762. (https://doi.org/10.1200/ JCO.2005.08.066)

Ladenson PW, Braverman LE, Mazzaferri EL, Brucker-Davis F, Cooper DS, Garber JR, Wondisford FE, Davies TF, DeGroot LJ, Daniels GH, et al. 1997 Comparison of administration of recombinant human thyrotropin with withdrawal of thyroid hormone for radioactive iodine scanning in patients with thyroid carcinoma. New England Journal of Medicine 337 888-896. (https://doi.org/10.1056/ NEJM199709253371304)

Mehnert JM, Monjazeb AM, Beerthuijzen JMT, Collyar D, Rubinstein L \& Harris LN 2017 The challenge for development of valuable immuno-oncology biomarkers. Clinical Cancer Research $\mathbf{2 3}$ 4970-4979. (https://doi.org/10.1158/1078-0432.CCR-16-3063) Nonnekens J, van Kranenburg M, Beerens CEMT, Suker M, Doukas M, van Eijck CHJ, de Jong M \& van Gent DC 2016 Potentiation of peptide receptor radionuclide therapy by the PARP inhibitor olaparib. Theranostics 6 1821-1832. (https://doi.org/10.7150/ thno.15311)

Purohit NK, Shah RG, Adant S, Hoepfner M, Shah GM \& Beauregard JM 2018 Potentiation of (177)Lu-octreotate peptide receptor radionuclide therapy of human neuroendocrine tumor cells by PARP inhibitor. Oncotarget 9 24693-24706. (https://doi.org/10.18632/ oncotarget.25266)

Raymond E, Dahan L, Raoul JL, Bang YJ, Borbath I, Lombard-Bohas C, Valle J, Metrakos P, Smith D, Vinik A, et al. 2011 Sunitinib malate for the treatment of pancreatic neuroendocrine tumors. New England Journal of Medicine 364 501-513. (https://doi.org/10.1056/ NEJMoa1003825)

Rolleman EJ, Melis M, Valkema R, Boerman OC, Krenning EP \& de Jong M 2010 Kidney protection during peptide receptor radionuclide therapy with somatostatin analogues. European Journal of Nuclear Medicine and Molecular Imaging 37 1018-1031. (https://doi. org/10.1007/s00259-009-1282-y)

Russell JS, Burgan W, Oswald KA, Camphausen K \& Tofilon PJ 2003 Enhanced cell killing induced by the combination of radiation and the heat shock protein 90 inhibitor 17-allylamino-17demethoxygeldanamycin: a multitarget approach to radiosensitization. Clinical Cancer Research 9 3749-3755.

Sandstrom M, Garske-Roman U, Granberg D, Johansson S, Widstrom C, Eriksson B, Sundin A, Lundqvist H \& Lubberink M 2013 Individualized dosimetry of kidney and bone marrow in patients undergoing 177Lu-DOTA-octreotate treatment. Journal of Nuclear Medicine 54 33-41. (https://doi.org/10.2967/jnumed.112.107524)

Spetz J, Langen B, Rudqvist N, Parris TZ, Helou K, Nilsson O \& ForssellAronsson E 2017 Hedgehog inhibitor sonidegib potentiates (177) Lu-octreotate therapy of GOT1 human small intestine neuroendocrine tumors in nude mice. BMC Cancer 17 528. (https:// doi.org/10.1186/s12885-017-3524-x)

Strosberg J, El-Haddad G, Wolin E, Hendifar A, Yao J, Chasen B, Mittra E, Kunz PL, Kulke MH, Jacene H, et al. 2017 Phase 3 trial of 177Lu-dotatate for midgut neuroendocrine tumors. New England Journal of Medicine 376 125-135. (https://doi.org/10.1056/ NEJMoa1607427)

Taelman VF, Radojewski P, Marincek N, Ben-Shlomo A, Grotzky A, Olariu CI, Perren A, Stettler C, Krause T, Meier LP, et al. 2016 Upregulation of key molecules for targeted imaging and therapy. Journal of Nuclear Medicine 57 1805-1810. (https://doi.org/10.2967/ jnumed.115.165092)

Veenstra MJ, van Koetsveld PM, Dogan F, Farrell WE, Feelders RA, Lamberts SWJ, de Herder WW, Vitale G \& Hofland LJ 2018 Epidruginduced upregulation of functional somatostatin type 2 receptors in human pancreatic neuroendocrine tumor cells. Oncotarget 9 14791-14802. (https://doi.org/10.18632/oncotarget.9462)

Weber J 2010 Immune checkpoint proteins: a new therapeutic paradigm for cancer - preclinical background: CTLA-4 and PD-1 blockade. Seminars in Oncology 37 430-439. (https://doi.org/10.1053/j. seminoncol.2010.09.005)

Weichselbaum RR, Liang H, Deng L \& Fu YX 2017 Radiotherapy and immunotherapy: a beneficial liaison? Nature Reviews. Clinical Oncology 14 365-379. (https://doi.org/10.1038/nrclinonc.2016.211)

Yao JC, Shah MH, Ito T, Bohas CL, Wolin EM, Van Cutsem E, Hobday TJ, Okusaka T, Capdevila J, de Vries EG, et al. 2011 Everolimus for advanced pancreatic neuroendocrine tumors. New England Journal of Medicine 364 514-523. (https://doi.org/10.1056/ NEJMoa1009290)

Received in final form 10 June 2019

Accepted 14 June 2019

Accepted Preprint published online 14 June 2019 https://erc.bioscientifica.com

https://doi.org/10.1530/ERC-19-0186 (c) 2019 Society for Endocrinology Published by Bioscientifica Ltd. Printed in Great Britain 